\title{
EVALUATION OF THE EFFECT OF PRF ON BONE HEALING IN DIABETIC ANIMALS AFTER PERIRADICULAR SURGERY
}

\author{
Mohammed Saad Easa ${ }^{* *}$, Moataz Bellah A. Alkhawas², Hany Gameil Gobran ${ }^{3}$, Taher Medhat Islam ${ }^{4}$
}

\begin{abstract}
Objective: was directed to evaluate platelet rich fibrin alone and in combination with xenograft as an alternative to bone substitute in treatment of critical sized bone defects in dogs. Subjects and methods: 8 dogs were selected for this study in which diabetes mellitus was induced. Root canal treatment was done in the $2^{\text {nd }}$ and $4^{\text {th }}$ premolar teeth of both sides then 4 critical sized bone defects were created in relation to the distal root of the selected teeth. According to the bone cavity filling materials there was 4 groups: xenograft, xenograft and PRF, PRF, and blood clot groups. Dogs were sacrificed at 4 days, 2, 5, and 9 weeks. The mandibles were harvested for DEXA evaluation. Results: bone density measurement at 9 weeks was significant with Xenograft and PRF group than Xenograft, PRF and blood clot groups. Whereas there was no significance between Xenograft and PRF groups. Conclusion: PRF is a valuable material that can be used as a sole grafting material in periradicular surgery to improve bone regeneration.
\end{abstract}

KEY WORDS: PRF, periradicular surgery, PRF sole grafting material, PRF and Xenograft combination

\section{INTRODUCTION}

Non-surgical retreatment of failed cases of conventional root canal treatment using recent equipment such as ultrasonic devices, magnification and $\mathrm{CBCT}$ (which resulted in better identification of the root canal anatomy) has shown significant improvemnt. However, even with the best efforts, some of these cases cannot be successfully managed through non-surgical retreatment which necessitates surgical intervention ${ }^{(1)}$. Surgical management of periradicular lesions results in bony defects of variable sizes around involved teeth apecies with the need for bone substitute to enhance bone regeneration in some cases $^{(2)}$. Bone regeneration can be induced through three different mechanisms: Osteogenesis, Osteoinduction, Osteoconduction ${ }^{(3)}$. The primary types of bone graft material are autogenous bone, allografts, xenografts, and alloplasts. The mechanisms by which the grafts act are normally determined by their origin and composition. Autogenous bone graft harvested from the same patient and forms new bone by osteogenesis, osteoinduction, and osteoconduction. Allografts harvested from cadavers and have osteoconductive and possibly osteoinductive properties. Xenografts/ alloplasts are typically only osteoconductive ${ }^{(4)}$. Unfortunately, autogenous bone grafting may increase patient morbidity due to the second wound

1. Assistant Lecturer Department of Endodontics, Faculty of Dentistry, Al-Azhar University, Cairo (boys)

2. Associate Professor and chair of Endodontic Department, Faculty of Dentistry, Al-Azhar University, Cairo (boys)

3. Associate Professor, Department of Oral Biology, Faculty of Dentistry, Al-Azhar University, Cairo (boys)

4. Professor of Endodontics, Department of Endodontics, Faculty of Dentistry, Al-Azhar University, Cairo (boys)

-Corresponding author: mohammedsaad53202@gmail.com

DOI: $10.21608 /$ ajdsm.2020.45472.1122 
for bone harvesting and bone substitutes may be the source of disease transmission ${ }^{(5)}$.

Diabetes mellitus which is a metabolic disorder results in chronic hyperglycemia with disturbances of carbohydrate, fat, and protein metabolism resulting from defects in insulin secretion, insulin action, or both. The effects of diabetes mellitus include long-term damage, dysfunction, and failure of various organs ${ }^{(6)}$. Prolonged uncontrolled diabetes leads to impaired wound healing, as a result of the defective immune response, impaired recruitment and defective angiogenesis within the wound site with an end result of impaired healing ${ }^{(7)}$.

Recently platelet rich fibrin (PRF) which is a healing biomaterial with great potential to induce both hard and soft tissue regeneration, without inflammatory reactions may be used to replace bone grafts or in combination with bone grafts, to promote hemostasis, healing, and maturation ${ }^{(8)}$. The literature is reached with case reports where PRF was used as a bone substitute but there is a shortage in the studies that describe this effect so, in this study PRF was used as a sole grafting material to evaluate its effect on bone healing in diabetic animals.

\section{SUBJECT AND METHODS}

\section{Animal model:}

The study was done based on ARRIVE guidelines and the acceptance obtained from the ethics committee of the Faculty of Dentistry, Al-Azhar University, Cairo (boys). Out of 11 dogs, 8 healthy adult male purpose-bred dogs within the same rang of age weighting from 15 to $20 \mathrm{Kg}$, free from any systemic diseases, had their vaccines were selected to be used in the study in which diabetes mellitus was induced. All dogs were bred and housed under similar conditions at $22^{\circ} \mathrm{C}$ room temperature, $40 \%$ humidity and 12 hours daylight cycle with a standard laboratory diet and water. All procedures were done in cooperation with veterinary team of the general veterinary hospital in $\mathrm{Al}$ abbasyya, Cairo, Egypt.

\section{Induction of diabetes mellitus:}

Diabetes mellitus was induced in the selected dogs by intraperitoneal injection of a solutions of alloxan (Research-Lab Fine Chem, Industries, Mumbai, India) $50 \mathrm{mg} / \mathrm{kg}$ body weight, given on three consecutive days. The preparation was used immediately after dissolution in $0.1 \mathrm{M}$ acetate buffer at $\mathrm{pH} 4.4$ according to the protocol prepared and confirmed ${ }^{(9)}$. Diabetes mellitus was confirmed by measuring blood glucose level using blood glucose meter in which one drop of dog's venous blood was drown and placed on a special strips connected to the glucose meter. Diabetes was considered when blood glucose level was above $220 \mathrm{mg} / \mathrm{ml}$ as the normal blood glucose level is about $80-120 \mathrm{mg} / \mathrm{dL}$.

\section{Preparation of dogs:}

All dogs were fasted 12 hours prior to anesthesia, and premedicated with intramascular injection of atropine (atropine sulphate; ADWIA Co., Cairo, Egypt) at dose of $0.04 \mathrm{mg} / \mathrm{Kg}$, followed by Xylaject (xylazine hydrochlorid; ADWIA Co., Cairo, Egypt.) at a dose of $1 \mathrm{mg} / \mathrm{Kg}$.

\section{Animal anesthetization}

General anesthesia was induced by intravenous injection of ketamine hydrochloride (Keiran;EIMC pharmaceuticals Co., Cairo, Egypt) at a dose of $10 \mathrm{mg} / \mathrm{Kg}$ per body weight and maintained with intravenous injection of thiopental sodium at dose of $2.5 \mathrm{mg} / \mathrm{kg}$. One third of the estimated dose was injected within 15 seconds, the remainder was administered slowly until loss of pedal, corneal reflexes, and development of shallow regular respiration.

\section{PRF preparation}

Following anesthetization of the dogs, PRF preparation was performed according to the PRF protocol prepared by Choukroun ${ }^{(10)}$ in which $10 \mathrm{~mm}$ of dog's venous blood were drown and centrifuged at $3000 \mathrm{rpm}$ for $10 \mathrm{~min}$ using a laboratory 
centrifuge (NF 800, Nuve, Ankara, Turkey). After centrifugation, the blood in the tube was separated into 3 distinct zones, upper layer of platelet poor plasma, PRF in the middle and RBC at the bottom. The tubes were maintained until the bony cavities were prepared.

\section{Preparation of operative field:}

All procedures were conducted under a clean aseptic protocol with the use of sterile materials and equipment in which the dog's mouth, head and neck were swapped with betadine solution (Nile Company for Pharmaceuticals and Chemical Industries, Cairo, Egypt) followed by wrapping the head and neck by sterile napkins. Endodontic treatment of dog's mandibular $2^{\text {nd }}$ and $4^{\text {th }}$ premolar teeth was done on both sides. Obturation of the mesial roots was done using cold lateral compaction technique while the distal roots were kept to be filled with orthograde MTA (Angelus, Londrina, Brazil) after bony cavity preparation step, then access cavity was temporary packed with Teflon.

\section{Surgical Procedures:}

Prior to surgical intervention, $1.8 \mathrm{ml}$ of $2 \%$ lidocaine with nor-epinephrine 1: 100,000 (Amriya pharm.ind, Alexandria- Egypt) was injected into the surgical area for local hemostasis and hydrodisection. Two separate three sided rectangular full thickness mucoperiosteal flaps were raised in relation to the selected teeth. Following flap elevation, a bony defects of $7 \times 7 \times 7 \mathrm{~mm}$ were created in relation to the distel roots of the selected teeth using a special templet with removal of the apical $1 / 3$ of the roots. Teflon was used to completely fill the bony cavity until the distal root canal was filled with MTA to avoid extrusion of the materials out the root, Then access cavity was filled with resin modified glass ionmer filling material (Dentsply Maillefer, Ballaigues,Switzerland). on the right side of the mandible, the defect related to the $2^{\text {nd }}$ premolar tooth was filled with Xenograft and the defect related to the $4^{\text {th }}$ premolar was with a mixture of PRF and xenograft while on the left side the defect related to the $2^{\text {nd }}$ premolar tooth was filled with PRF and the defect related to the $4^{\text {th }}$ premolar was left empty to be filled with blood clot. Following the procedure of filling the bony defect the flap was repositioned and sutured with 3-0 resorbable suture vicryl ( polyglactin 910, Ethicon, Inc 2018) mounted on $19 \mathrm{~mm} \mathrm{3/8c}$ reverse cutting needle.

\section{Post-surgical Care}

The dogs were received amoxicillin and flucloxacillin (Flummox: E.I.P.I.co, 10 ${ }^{\text {th }}$ of Ramadan city-industrial area, Egypt) as antibiotics at a dose of $50 \mathrm{mg} / \mathrm{kg}$ per lean body weight per day and xylazine hydrochloride (Xylaject; ADWIA Co., Cairo, Egypt.), $3 \mathrm{ml}$ intramuscularly every 12 hours, for 5 days to control pain and infection under supervision of the vet physician. Dogs were kept on soft diet composed of milk, rice, meat, liver, and bread for the first post- operative week. On the second postoperative week, dogs were able to eat the usual diet. All the animals were evaluated clinically for assessments of the general health until scarification. Also daily examination was carried out for the presence of signs of infection as redness, hotness, ability of the mouth opening, eating, and swallowing.

\section{Scarification and Sample Harvesting:}

Euthanasia was scheduled at time table of 4 days, 2, 6, and 9 weeks after surgery in which two dogs were sacrificed at each time, under general anesthesia provided by intravenous injection of pentobarbital (Socumb, Butler Company, Columbus, Ohio) at $30 \mathrm{mg} / \mathrm{kg}$. The carotid arteries were exposed and cannulated then the dogs were euthanized with additional pentobarbital at a dose of $90 \mathrm{mg} / \mathrm{kg}$. The animals were perfused with $10 \%$ buffered formalin (Fisher Scientific, Fair Lawn, New Jersey). The mandible was surgically removed and maintained in $10 \%$ buffered formalin until the time of bone density measurement. 


\section{Densitometric analysis (DEXA)}

The mandible of each dog was referred freshly for bone density examination at the bone defect site, by using dual-energy X-ray absorptiometry (DEXA). These measures were done using a three sites axial scanner, bone mineral analyzer (lunar prodigy primo) at Raba hospital Radiology center, Nasr city, Cairo, Egypt. The bone mineral density (BMD) of each bone defect was measured at the $7 \times$ $7 \mathrm{~mm}^{2}$ region of interest by DEXA. This device was calibrated with a phantom of known mineral content. On the monitor, partial acquisition of images was shown while the scanner precede to analysis mode. When the scan finished the densitometric images saved and printed. All data were collected, tabulated, and statistically analyzed.

Data were explored for normality using Kolmogorov-Smirnov and Shapiro-Wilk tests, data showed non-parametric distribution. Friedman test was used to compare between more than two groups in related samples. Wilcoxon test was used to compare between two groups in related samples. Kruskal Wallis test was used to compare between more than two groups in non-related samples. Mann Whitney test was used to compare between two groups in non-related samples. The significance level was set at $P \leq 0.05$. Statistical analysis was performed with IBM ${ }^{\circledR}$ SPSS ${ }^{\circledR}$ Statistics Version 20 for Windows.

\section{RESULTS}

TABLE (1) Mean and standard deviation values for bone density at different scarification periods with the different materials.

\begin{tabular}{|c|c|c|c|c|c|c|c|c|}
\hline \multirow{4}{*}{ Variables } & \multicolumn{8}{|c|}{ Bone mineral density } \\
\hline & \multicolumn{8}{|c|}{ Diabetic animal } \\
\hline & \multicolumn{2}{|c|}{$\mathbf{X}$} & \multicolumn{2}{|c|}{$\mathrm{X}$ and PRF } & \multicolumn{2}{|c|}{ PRF } & \multicolumn{2}{|c|}{ Blood clot } \\
\hline & Mean & SD & Mean & SD & Mean & SD & Mean & SD \\
\hline days 4 & $0.623^{\mathrm{b}}$ & 0.012 & $0.511^{\mathrm{b}}$ & 0.001 & $0.133^{b}$ & 0.012 & $0.082^{b}$ & 0.024 \\
\hline weeks 2 & $0.654^{\mathrm{b}}$ & 0.024 & $0.674^{\mathrm{ab}}$ & 0.071 & $0.194^{b}$ & 0.012 & $0.112^{b}$ & 0.012 \\
\hline weeks 5 & $0.796^{\mathrm{a}}$ & 0.024 & $0.776^{\mathrm{ab}}$ & 0.047 & $0.669^{\mathrm{a}}$ & 0.184 & $0.217^{\mathrm{a}}$ & 0.031 \\
\hline weeks 9 & $0.720^{\mathrm{a}}$ & 0.054 & $0.887^{\mathrm{a}}$ & 0.059 & $0.582^{\mathrm{a}}$ & 0.035 & $0.255^{\mathrm{a}}$ & 0.035 \\
\hline p-value & \multicolumn{2}{|c|}{ 0.099* } & \multicolumn{2}{|c|}{$0.009 *$} & \multicolumn{2}{|c|}{$0.013 *$} & \multicolumn{2}{|c|}{ 0.013* } \\
\hline
\end{tabular}

Means with different small letters indicate significant difference *; significant $(p<0.05)$ ns; non-significant $(p>0.05)$

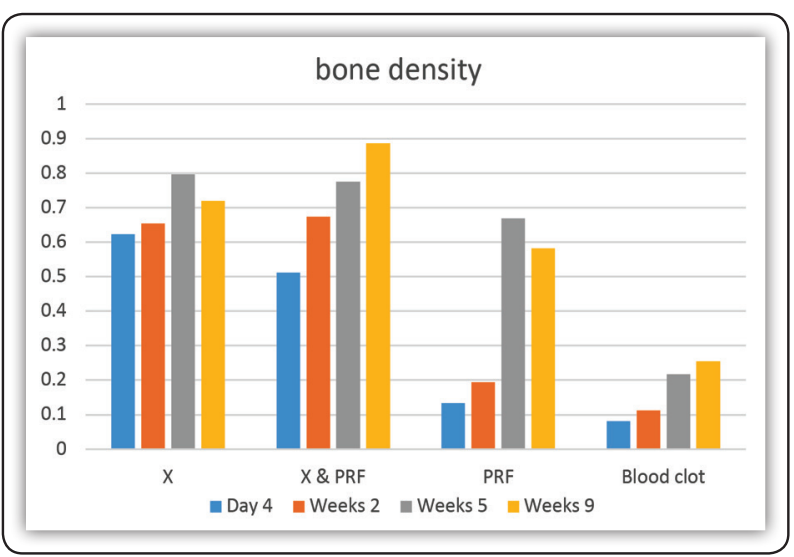

FIG (1) Bar chart represent bone density at different scarification periods with the different materials.
A statistically significant difference was found between xenograft \& PRF group $(0.435 \pm 0.029)$ and each of xenograft $(0.35 \pm 0.023), \quad$ PRF $(0.285 \pm 0.017)$ and blood clot $(0.125 \pm 0.017)$ groups where $(\mathrm{p}=0.001),(\mathrm{p} 0.006)$ and $(p<0.001)$. Also, a statistically significant difference was found between blood clot $(0.125 \pm 0.017)$ and each of $\mathrm{x}$ and PRF $(0.435 \pm 0.029)$ and PRF $(0.285 \pm 0.017)$ groups where $(p<0.001)$. 


\section{DISCUSSION}

Diabetes mellitus may affects the process of wound healing as it affects blood flow, and impairs the boy anti-microbial activity. Also it was found that a number of growth factors essential for wound healing, including FGF-2 and PDGF-B, have been reduced in experimental diabetic wounds ${ }^{(11-14)}$ all of this factor lead to increased incidence of infection after surgery $^{(15)}$. Periradicular lesion of pulpal origin have been noticed in $74-97 \%$ of the diabetic patient those have teeth with symptomatic pulpitis ${ }^{(16-18)}$.

Critical-sized bony defect was defined as the bony defect that does not heal over lifetime of the animal. Later on critical sized bone defect was redefined as the size of a defect that will not heal over the duration of the study, this is because most studies are of limited duration and does not extend over the entire life of the animal ${ }^{(19)}$. The goal of this study was to create a bony defect that unable to heal on its own through the study time, similar to human non unions so a bony defect of $7 \times 7 \times 7$ $\mathrm{mm}$ was created. PRF was considered as a healing biomaterial because it is constituted by a fibrin network in which platelets, leukocytes, cytokines and stem cells are enmeshed. PRF contains nearly $97 \%$ of platelets and more than 50\% of leukocytes ${ }^{(20)}$. PRF also enmeshes glycosaminoglycans which has a great capacity to support cell migrations and healing processes ${ }^{(18,21-23)}$. Regarding the effect of time, on bone mineral content, bone mineral density and woven bone formation, 9 weeks period showed the highest result in relation to other time periods, and this results is logical in which bone density will increased as the time for healing increase.

Regarding the effect of testing materials, Xenograft group was significant at 4 days, 2 weeks than other groups as the material itself has a high mineral content so its effect was present from day one, while PRF is considered as a soft tissue which exhibit low intensity signals on X-ray scanning immediately after application ${ }^{(24)}$. At 5 weeks there was no difference between Xenograft \&PRF and Xenograft groups. While at 9 weeks Xenograft \&PRF group showed significant difference and there was no difference between Xenograft and PRF groups ${ }^{(25)}$. Studies showed that PRF act as an appropriate scaffold with a strong fibrin structure that optimally support the transplanted mesenchymal cells and allow for gradual release of growth factors over a long period ranging from 7 to 28 days ${ }^{(26-29)}$. Also it was found that PRF has a role in phosphorylated extracellular signal-regulated protein kinase expression and suppress osteoclastogenesis by promoting the secretion of osteoprotegerin in osteoblasts cultures ${ }^{(30)}$.

Combining PRF with bone grafts is advantageous to other platelet preparations in stabilizing the grafting material at the defect site along with growth factors included in the platelets, leukocytes $\&$ fibrin network ${ }^{(31)}$. Recently this combination was considered as a regenerative material showed enhanced healing of both hard \& soft tissue ${ }^{(32)}$. Also it was found that Adding PRF to bone sub statute particles significantly reduce the time required to promote graft consolidation, maturation, and improved trabecular bone density ${ }^{(33)}$.Beside that, PRF may hasten natural healing in immuno-compromised patients, and those with a history of radiotherapy because it is able to stimulate natural defiance mechanisms ${ }^{(34)}$. As minimal cost is involved, it can be used for all types of patients ${ }^{(35)}$.

It has been found that, topical application of VEGF in diabetics enhances neovascularization at the site of injury with a clinically significant effect. The mechanism for this effect is through a stimulation of local angiogenesis, enhanced expression of growth factors including PDGF and FGF-2, and a systemic mobilization of bone marrow-derived stem cells ${ }^{(36)}$, PRF is rich of this growth factors.

\section{CONCLUSION}

PRF can be used as a sole grafting material for bone regeneration in periradicular surgeries associated with large bone defects and when PRF added to a bone substitute they result in better induction of bone healing. 


\section{REFERENCES}

1. Carrillo-García C, Vera-Sempere F, Peñarrocha-Diago M, Martí-Bowen E. The post-endodontic periapical lesion: Histologic and etiopathogenic aspects. Med Oral Patol Oral Cir Bucal. 2007 1;12(8):585-90.

2. Saunders JA. prospective clinical study of periapical surgery using Mineral Trioxide Aggregate as a root end filling. J. Endod 2008; 34:660 -5.

3. Misch CE, Dietsh F. Bone-grafting materials in implant dentistry. Implant Dent 1993; 2: 158-67.

4. Liu J, Kerns DG.Mechanisms of Guided Bone Regeneration: A Review. The Open Dentistry Journal, 2014, 8, (Suppl 1-M3) 56-65

5. Quattlebaum JB, Mellonig JT, Hensel NF. Antigenicity of freezedried cortical bone allograft in human periodontal osseous defects. J Periodontol 1988; 59: 394-7.

6. World Health Organization Geneva (1999). Definition, Diagnosis and Classification of Diabetes Mellitus and its Complications: Report of a WHO Consultation. Part 1: Diagnosis and Classification of Diabetes Mellitus. World Health Org.

7. Waltenberger J, Lange J, Kranz A. Vascular endothelial growth factor-A-induced chemotaxis of monocytes is attenuated in patients with diabetes mellitus: a potential predictor for the individual capacity to develop collaterals. Circulation. 2000;11:102:185-90.

8. Dohan DM, Choukroun J, Diss A. Platelet-rich fibrin (PRF): a second generation platelet concentrate-part I: technological concept and evolution. Oral Surg Oral Med Oral Path Oral Radiol Endod 2006;101:37-44

9. Rohilla A, Ali S. Alloxan induced diabetes: mechanisms and effects. International journal of research in pharmaceutical and biomedical sciences. 2012 Apr;3(2):819-23.

10. Saluja H, Dehane V, Mahindra U. Platelet-Rich fibrin: A second generation platelet concentrate and a new friend of oral and maxillofacial surgeons. Annals of maxillofacial surgery. 2011;1(1):53.

11. Beer HD, Longaker MT, Werner S. Reduced expression of PDGF and PDGF receptors during impaired wound healing. J Invest Dermatol 1997;109:132-38.

12. Werner S, Breeden M, Hubner G, Greenhalgh DG, Longaker MT. Induction of keratinocyte growth factor expression is reduced and delayed during wound healing in the genetically diabetic mouse. J Invest Dermatol 1994; 103:469-73.
13. Bitar MS, Labbad ZN. Transforming growth factor-beta and insulinlike growth factor-I in relation to diabetesinduced impairment of wound healing. J Surg Res 1996, 61:113-119.

14. Brown DL, Kane CD, Chernausek SD, Greenhalgh DG. Differential expression and localization of insulin-like growth factors I and II in cutaneous wounds of diabetic and nondiabetic mice. Am J Pathol 1997, 151:715-24.

15. American Diabetes Association. Diagnosis and Classification of Diabetes Mellitus. Diabetes Care 2012; 35: S64-71.

16. Britto LR, Katz J, Guelmann M, Heft M. Periradicular radiographic assessment in diabetic and control individuals. Oral Surg Oral Med Oral Pathol Oral Radiol Endod 2003; 96: 449-52.

17. López-López J, Jané-Salas E, Estrugo-Devesa A, VelascoOrtega E, Martín-González J, Segura-Egea JJ. Periapical and endodontic status of type 2 diabetic patients in Catalonia, Spain: a cross-sectional study. Journal of endodontics. 2011 May 1;37:598-601.

18. Mesgarani A, Haghanifar S, Eshkevari N, Ehsani M, Khafri S, Nafarzade S, Damankesh Z. Frequency of odontogenic periradicular lesions in diabetic patients. Caspian journal of internal medicine. 2014;5:22.

19. Gosain AK, Song L, Yu P, Mehrara BJ, Maeda CY, Gold LI, Longaker MT. Osteogenesis in cranial defects: reassessment of the concept of critical size and the expression of TGF-beta isoforms. Plast Reconstr Surg 2000; 106:360-371.

20. Dohan Ehrenfest DM, Del Corso M, Diss A, Mouhyi J, Charrier JB. Three-dimensional architecture and cell composition of a Choukroun's platelet-rich fibrin clot and membrane. Journal of periodontology. 2010; 81:546-55.

21. Clark RA. Fibrin and wound healing. Ann N Y Acad Sci 2001; 936:355-67.

22. Dohan DM, Choukroun J, Diss A, Dohan SL,Dohan AJ, Mouhyi J, Gogly B. Platelet-rich fibrin (PRF): a secondgeneration platelet concentrate. Part II: platelet-related biologic features. Oral Surg Oral Med Oral Pathol Oral Radiol Endod 2006; 101:e45-50.

23. Choukroun J, Diss A, Simonpieri A, Girard MO, Schoeffler C, Dohan SL. Platelet-rich fibrin (PRF): A secondgeneration platelet concentrate. Part V: Histologic evaluations of PRF effects on bone allograft maturation in sinus lift. Oral Surg Oral Med Oral Pathol Oral Radiol Endod.2006;101:299-303. 
24. Chang YC, Wu KC 1, Zhao JH. Clinical application of platelet-rich fibrin as the sole grafting material in periodontal intrabony defects. Journal of Dental Sciences 2011; 6: 181-88

25. Kumar YR, Mohanty S, Verma M, Kaur RR, Bhatia P, Kumar VR, Chaudhary Z. Platelet-rich fibrin: the benefits. British Journal of Oral and Maxillofacial Surgery. 2016; 54:57-61.

26. Ehrenfest DM, Diss A, Odin G, Doglioli P, Hippolyte MP, Charrier JB. In vitro effects of Choukroun's PRF (plateletrich fibrin) on human gingival fibroblasts, dermal prekeratinocytes, preadipocytes, and maxillofacial osteoblasts in primary cultures. Oral Surgery, Oral Medicine, Oral Pathology, Oral Radiology, and Endodontology. 2009 Sep 1;108(3):341-52.

27. He L, Lin Y, Hu X, Zhang Y, Wu H. A comparative study of platelet-rich fibrin (PRF) and platelet-rich plasma (PRP) on the effect of proliferation and differentiation of rat osteoblasts in vitro. Oral Surgery, Oral Medicine, Oral Pathology, Oral Radiology, and Endodontology. 2009;108:707-13.

28. Mazor Z, Horowitz R A, Del Corso M, Prasad HS, Rohrer M D, Dohan Ehrenfest DM. Sinus floor augmentation with simultaneous implant placement using Choukroun's platelet-rich fibrin as the sole grafting material: a radiologic and histologic study at 6 months. Journal of periodontology. 2009; 80:2056-64.

29. Tsai CH, Shen S Y, Zhao J H, Chang Y C. Platelet-rich fibrin modulates cell proliferation of human periodontally related cells in vitro. J Dent Sci 2009;4:130-35

30. Chang IC, Tsai CH, Chang YC. Platelet-rich fibrin modu- lates the expression of extracellular signal-regulated protein kinase and osteoprotegerin in human osteoblasts. J Biomed Mater Res A 2010;95:327-32.

31. Sohn DS, Huang B, Kim J, Park WE, Park CC. Utilization of autologous concentrated growth factors (CGF) enriched bone graft matrix (Sticky bone) and CGF-enriched fibrin membrane in Implant Dentistry. J Implant Adv Clin Dent. 2015;7:11-29.

32. Moheb ME, Al-Zarea B, Sghaireen MG, Toriya J, Mizohata A, Patil S, Siada A, Brad B, Kochaji N, Alam MK, Osuga N. Mineralized plasmatic matrix to enhance the bone grafting technique. Journal of Hard Tissue Biology. 2017;26:289-92.

33. Yilmaz D, Dogan N, Ozkan A, Sencimen M, Ora BE, Mutlu I. Effect of platelet rich fibrin and beta tricalcium phosphate on bone healing. A histological study in pigs. Acta Cirurgica Brasileira. 2014 ;29:59-65.

34. Gaßling VL, Açil Y, Springer IN, Hubert N, Wiltfang J. Platelet-rich plasma and platelet-rich fibrin in human cell culture. Oral Surgery, Oral Medicine, Oral Pathology, Oral Radiology, and Endodontology. 2009;108:48-55.

35. Kumar YR, Mohanty S, Verma M, Kaur RR, Bhatia P, Kumar VR, Chaudhary Z. Platelet-rich fibrin: the benefits. British Journal of Oral and Maxillofacial Surgery. 2016;54:57-61.

36. Galiano RD, Tepper OM, Pelo CR, Bhatt KA, Callaghan M, Bastidas N, Bunting S, Steinmetz HG, Gurtner GC. Topical vascular endothelial growth factor accelerates diabetic wound healing through increased angiogenesis and by mobilizing and recruiting bone marrow-derived cells. The American journal of pathology. 2004; 164:1935-47. 